\title{
R-Baclofen Reverses Cognitive Deficits and Improves Social Interactions in Two Lines of I6pII.2 Deletion Mice
}

\author{
Laura J Stoppel 1,3, Tatiana M Kazdoba ${ }^{2,3,4}$, Melanie D Schaffler ${ }^{2,3}$, Anthony R Preza', Arnold Heynen', \\ Jacqueline N Crawley ${ }^{2,5}$ and Mark F Bear ${ }^{*, 1,5}$ \\ 'The Picower Institute for Learning and Memory, Department of Brain and Cognitive Sciences, Massachusetts Institute of Technology, Cambridge, \\ MA, USA; ${ }^{2}$ MIND Institute, Department of Psychiatry and Behavioral Sciences, University of California Davis School of Medicine, Sacramento, CA, \\ USA
}

\begin{abstract}
Human chromosome I6p I I.2 microdeletion is among the most common gene copy number variations (CNVs) known to confer risk for intellectual disability (ID) and autism spectrum disorder (ASD) and affects an estimated 3 in 10000 people. Caused by a single copy deletion of $\sim 27$ genes, $16 \mathrm{pl}$ I.2 microdeletion syndrome is characterized by ID, impaired language, communication and socialization skills, and ASD. Studies in animal models where a single copy of the syntenic $16 \mathrm{p} / 1.2$ region has been deleted have revealed morphological, behavioral, and electrophysiological abnormalities. Previous studies suggested the possibility of some overlap in the mechanisms of pathophysiology in 16 | I.2 microdeletion syndrome and fragile $X$ syndrome. Improvements in fragile $X$ phenotypes have been observed following chronic treatment with $R$-baclofen, a selective agonist of $G A B A_{B}$ receptors. We were therefore motivated to investigate the effects of chronic oral R-baclofen administration in two independently generated mouse models of I6p I I.2 microdeletion syndrome. In studies performed across two independent laboratories, we found that chronic activation of GABA $A_{B}$ receptors improved performance on a series of cognitive and social tasks known to be impaired in two different $16 \mathrm{p} \mid 1.2$ deletion mouse models. Our findings suggest that $R$ baclofen may have clinical utility for some of the core symptoms of human $16 \mathrm{p} \mid 1.2$ microdeletion syndrome.

Neuropsychopharmacology (2018) 43, 513-524; doi:I0.1038/npp.20 I7.236; published online I5 November 2017
\end{abstract}

\section{INTRODUCTION}

Several conceptual frameworks have been introduced to explain how a growing list of diverse gene mutations and environmental factors manifest as similar neurodevelopmental disorders with intellectual disability (ID) and autism. Among these is the prominent theory that autistic features arise from alterations in the balance of excitation to inhibition in mature cortical microcircuitry (Gogolla et al, 2009; Rubenstein and Merzenich, 2003). Another is the concept, based on research in animal models of several genetically defined syndromic forms of ID and autism spectrum disorder (ASD), that synaptic function and plasticity are impaired by dysregulation of neuronal proteostasis (Bear et al, 2004; Kelleher and Bear, 2008; Louros and Osterweil, 2016). These frameworks are not mutually exclusive. Consequences of altered protein synthesis regulation could include derailed development of

*Correspondence: Professor MF Bear, The Picower Institute for Learning and Memory, Department of Brain and Cognitive Sciences, Massachusetts Institute of Technology, Cambridge, MA 02139, USA, Tel: + | 617324 7002, Fax: + I 617324 7007, E-mail: mbear@mit.edu

${ }^{3}$ These authors contributed equally to this work.

${ }^{4}$ Current address: Sage Therapeutics, Cambridge, MA, USA

${ }^{5}$ These senior authors contributed equally to this work.

Received 25 May 2017; revised 16 August 2017; accepted 25 September 2017; accepted article preview online 6 October 2017 excitation-inhibition (E-I) balance, and because neuronal protein synthesis is under tight regulation by glutamatergic synaptic transmission, an increased E-I ratio could manifest as aberrant protein synthesis. In either case, there is a strong rationale for examining treatment strategies based on boosting inhibition relative to excitation, at least for some causes of ID and ASD.

To date, this approach has been most fully explored in animals and humans with fragile X syndrome (FXS). FXS is caused by silencing of the FMR1 gene that encodes the mRNA-binding protein FMRP. It has been shown that one important function of FMRP is to repress activity-dependent neuronal protein synthesis (Santoro et al, 2012). In animal models in which the gene has been knocked out, altered protein synthesis and a large number of disease phenotypes can be corrected either by reducing glutamate signaling via metabotropic glutamate receptor 5 (mGluR5) (Dolen et al, 2007; Michalon et al, 2012; Stoppel et al, 2017) or by boosting inhibition via $\mathrm{GABA}_{\mathrm{B}}$ receptors (Henderson et al, 2012; Qin et al, 2015). The $\mathrm{GABA}_{\mathrm{B}}$ agonist used for these preclinical studies was $R$-baclofen, the active enantiomer of baclofen. Racemic baclofen has been extensively used clinically for the treatment of spasticity in cerebral palsy and multiple sclerosis (Ertzgaard et al, 2017; Rizzo et al, 2004). The well-known safety profile of the racemic mixture made $R$-baclofen an attractive clinical candidate for early interventions in neurodevelopmental disorders (the clinical 
formulation of $R$-baclofen is also called arbaclofen or STX209). Several clinical trials have now been completed for both FXS and idiopathic autism (Berry-Kravis et al, 2017a,c; Berry-Kravis et al, 2012; Veenstra-VanderWeele et al, 2017). Although no significant improvements over placebo were observed using the predetermined primary end points, efficacy signals were observed on physician-rated global assessments in all four trials. Interestingly, the nominally significant change observed in the autism trial was driven by a strong response in a subset of participants (Veenstra-VanderWeele et al, 2017). These individuals may have responded to treatment because they represent a subset that shares some pathophysiological features with FXS.

In an effort to understand the degree to which different identified causes of autism and ID converge onto a common set of pathophysiological processes, over the past several years our laboratories have compared several different genetically defined mouse models (Auerbach et al, 2011; Barnes et al, 2015; Dhame et al, 2017; Portmann et al, 2014; Silverman et al, 2015; Silverman et al, 2012; Tao et al, 2016; Tian et al, 2015; Yang et al, 2015a,b). Among these were mouse models of human chromosome 16p11.2 microdeletion. Humans with $16 \mathrm{p} 11.2$ microdeletion syndrome are hemizygous in a region comprising $\sim 27$ protein-coding genes and show impairments in adaptive function that prominently include ID. Full-scale IQ is decreased by $\sim 2 \mathrm{SD}$, such that $70 \%$ of deletion carriers have an IQ $<85$ (Zufferey et al, 2012). Additional features of 16p11.2 microdeletion syndrome can include speech and language disruptions and ASD, along with an increased incidence of seizures, larger head size and body weight, developmental coordination and anxiety disorders (Bernier et al, 2017; Hanson et al, 2015; Hippolyte et al, 2016; Moreno-De-Luca et al, 2015). Several mouse models have been created that carry a heterozygous deletion of the same genes on mouse chromosome $7 \mathrm{qF} 3$, the syntenic region of human chr16p11.2. Studies in one of these revealed, surprisingly, a synaptic plasticity phenotype that closely resembles the $F m r 1^{-l y}$ mouse (Tian et al, 2015). These findings prompted us to ask if behavioral phenotypes in these mice might similarly be improved by $R$-baclofen, in which case this treatment might be considered for further investigation in the well-characterized $16 \mathrm{p} 11.2$ subgroup of patients.

Three models of the human 16p11.2 deletion have been established and characterized (Arbogast et al, 2016; Horev et al, 2011; Portmann et al, 2014). These mice all carry highly similar (with subtle differences in regional overlap) heterozygous deletion of the syntenic region of human chromosome 16p11.2 (Arbogast et al, 2016; Horev et al, 2011; Portmann et al, 2014). Confidence in a drug response in an animal model is strongest when phenotypes and therapeutic efficacy replicate across laboratories. Corroborative findings from two separately generated lines of mice with the same mutation offer an even higher standard of reproducibility. Here we employ two independent lines of 16p11.2 deletion mice (termed 16p11.2 df/t), tested in two independent laboratories, to evaluate the therapeutic potential of $R$-baclofen on autism-relevant behavioral phenotypes.

\section{MATERIALS AND METHODS}

\section{Bear Laboratory, Massachusetts Institute of Technology, Cambridge, MA}

Mice and treatment. A mouse line carrying a microdeletion of mouse chromosome $7 \mathrm{qF} 3$, the syntenic region of human chr16p11.2, was generously provided by Professor Alea Mills from the Cold Spring Harbor Laboratory (Horev et al, 2011). To supplement the colony, F3 heterozygous 16 p11.2 heterozygous male mice on a mixed 129/C57BL/6 background were backcrossed $>3$ generations to C57BL/6J mice from Charles River Laboratory. All mice were grouphoused on a $12 \mathrm{~h}$ on/12 h off light/dark cycle. Both male and female $16 \mathrm{p} 11.2 \mathrm{df} /+$ mice were crossed to male or female wild-type (WT) mice to generate $+/+$ and $d f /+$ littermates. There was no discernable difference in survival between $+/+$ and $d f /+$ littermates; however, progeny did not follow Mendelian ratios as previously described (Tian et al, 2015). All littermates were weaned at P21 and only male mice were used for behavioral testing. Most animals were tested on open field habituation, novel object recognition, and context discrimination, in that order. Because the context discrimination task required more animals, an additional cohort was exposed to that task. All experiments were conducted in accordance with the rules and regulations of the NIH Guide for the Care and Use of Laboratory Animals and approved by the Institutional Animal Care and Use Committee at MIT. All experiments were performed by an experimenter blind to genotype and treatment.

To provide continuous exposure and obviate the need for daily injections, $R$-baclofen (generously supplied by the Simons Foundation Autism Research Initiative) was administered in the drinking water as described by Henderson et al (2012). As mice were group housed in mixed genotype cages, individual consumption volumes could not be determined. However, administration in the drinking water at $0.5 \mathrm{mg} / \mathrm{ml}$ has been shown to provide on average a brain exposure equivalent to $6 \mathrm{mg} / \mathrm{kg}$ administered by intraperitoneal injection twice a day, which is sufficient to engage $\mathrm{GABA}_{\mathrm{B}}$ receptors and reduce excessive protein synthesis in the Fmr1 ${ }^{-/ y}$ mice. Vehicle (drinking water) and R-baclofentreated water were given ad libitum and changed daily for the duration of the experiment. Animals were given vehicle or $R$ baclofen for at least 12 days prior to behavioral testing. Vehicle or $R$-baclofen administration continued in the drinking water throughout behavioral testing, which was conducted in the sequence described below.

Open field habituation task. Open field habituation task was performed in a $40 \times 40 \times 40 \mathrm{~cm}^{3}$ box during $2 \times 15$-min habituation sessions, spaced $1-2 \mathrm{~h}$ apart. Animals at 8-12 weeks of age were placed in the behavior box and allowed to explore freely during each habituation session. Sessions were recorded and locomotor activity was tracked using Plexon's CinePlex Studio and analyzed using Plexon's CinePlex Editor and code written in MATLAB. For analysis, the box was divided into two zones: an 'inner' zone (containing the inner $30 \times 30 \mathrm{~cm}^{2}$ center square) and an 'outer' zone (the outermost area $5 \mathrm{~cm}$ from the walls). Total distance traveled was computed as the sum of distance covered over the course of each habituation session. 
Novel object recognition. The novel object recognition task was adapted from experiments previously described (Leger et al, 2013). Animals at 8-12 weeks of age were habituated to a $40 \times 40 \times 40 \mathrm{~cm}^{3}$ box during $2 \times 15-\mathrm{min}$ sessions, spaced 1-2 $\mathrm{h}$ apart. Animals were returned to their home cage in between session. Twenty-four hours after habituation, animals were exposed to two identical objects for $2 \times 10 \mathrm{~min}$ exploration sessions in the same box, spaced 1-2 $\mathrm{h}$ apart. Animals were required to explore each object for at least $10 \mathrm{~s}$ (for a total of at least $20 \mathrm{~s}$ ) in the first session to be included in the subsequent sessions. Twenty-four hours after object exploration, one object was replaced with a novel object and the animals were allowed to explore the objects for $10 \mathrm{~min}$. Time spent exploring was recorded during this exploration period and was characterized by sniffing within $2 \mathrm{~cm}$ of each object or directly touching the objects. Time spent climbing or on top of the objects was not included. Familiar and novel object and side placement was randomly assigned, by animal. Discrimination index was calculated as ((time spent exploring novel object)/(time spent exploring novel object+time spent exploring familiar object)).

Contextual discrimination task. Context discrimination was performed in a Freezeframe Chamber (Coulbourn Instrument) as previously described (Auerbach et al, 2011; Ehninger et al, 2008). Briefly, 6-12-week-old wild-type and $16 \mathrm{p} 11.2$ heterozygous male mice were fear conditioned on day 1 and the subsequent percentage of time spent freezing in either the familiar or a novel context was determined $24 \mathrm{~h}$ later. On the day of conditioning, animals were allowed to explore the behavioral chamber for $3 \mathrm{~min}$, followed by delivery of a $2 \mathrm{~s}, 0.8 \mathrm{~mA}$ foot shock. Mice remained in the context for $15 \mathrm{~s}$ after the shock before being returned to their home cages. Fear response was assessed $24 \mathrm{~h}$ later. To determine context specificity of the conditioned response, mice trained on day 1 were separated into two groups on day 2: one group was tested in the same training context (familiar context), and the other tested in a novel context. The novel context was created by varying spatial cues (taping pink cage cards on the walls of the environment), floor material (grid rather than barred), and lighting (red light rather than white light) of the testing chamber. The percentage of time a mouse spent freezing during the 3 min test session on day 2 was the behavioral readout. Statistical significance was determined using repeated measures two-way ANOVA and post hoc Student's $t$-tests.

Statistical analysis. Object recognition data were analyzed using paired $t$-test, comparing the number of seconds spent sniffing each object within genotype and within treatment, during the familiarization and novel object recognition phases. Discrimination index was analyzed using unpaired $t$-tests and two-way ANOVA, genotype $\times$ treatment. Contextual discrimination task data were analyzed using unpaired $t$-tests (for pairwise comparisons), comparing the percentage of time spent freezing between mice placed in the familiar context $v s$ the novel context by genotype. Additionally, data were analyzed using a three-way ANOVA for genotype, treatment, and context. Open field habituation data were analyzed using a paired $t$-test to compare the percentage of time spent in the inner and outer zones within each group and an unpaired $t$-test to compare distance travelled or zone preference between groups. Additionally, within each treatment condition, data were analyzed using a three-way ANOVA for genotype, zone, and session. Within the vehicle-treated cohort, additional pairwise multiple comparison procedures were also performed (Holm-Sidak method).

\section{Crawley Laboratory, MIND Institute, University of California Davis, Sacramento, CA}

Mice and treatment. 16p11.2 deletion mice, generated and generously provided by Thomas Portmann and Ricardo Dolmetsch at Stanford University, were rederived at the University of California Davis in Sacramento. Wild-type $(+/+)$ female mice were mated with heterozygous $(+/-)$ males to produce $+/+$ and $+/$ - littermates of both sexes for behavioral testing. The reciprocal cross was not employed because pup survival was low in litters born to female $+/-$ dams. Genotypes were identified by visualizing mCherry expression with a DFP-1 dual fluorescent protein flashlight (http://www.nightsea.com/products/dfp-1/ Nightsea, Bredford, MA), as previously described (Yang et al, 2015a, b). Wild-type pups were weaned at 21 days of age and heterozygous mice were weaned at up to 35 days to reduce nutrition-related fatalities. Mice were housed by sex in cages of 2-4 littermates, maintained in a temperature-controlled vivarium, lights on at 0700 hours and off at 0700 hours, with ad libitum access to food. All procedures were conducted in accordance with the NIH Guide for the Care and Use of Laboratory Animals and approved by the University of California Davis Institutional Animal Care and Use Committee.

$R$-baclofen (generously supplied by the Simons Foundation Autism Research Initiative) was delivered in the home cage drinking water via Falcon $50 \mathrm{ml}$ conical centrifuge tubes, beginning 1 week before the start of behavioral testing. Vehicle or $R$-baclofen administration continued in the drinking water throughout behavioral testing, which was conducted in the sequence described below. Drinking water contained either a $1 \%$ saccharin solution (control) or solution of $0.5 \mathrm{mg} / \mathrm{ml} R$-baclofen in $1 \%$ saccharin (experimental). Saccharin was added to improve palatability of $R$ baclofen. Animal weight was measured and recorded daily to monitor possible dehydration using an Ohaus CL201 portable balance. Amount of drinking water consumed per cage was measured daily, using the gradation lines on the Falcon tubes. As mice were group housed in mixed genotype cages, individual consumption volumes could not be determined. Fresh vehicle and $R$-baclofen solutions were added daily. $R$-baclofen treatment reduced consumption and body weights in both genotypes during the initial days of treatment, after which volumes consumed were similar to untreated water, and body weights returned to a normal trajectory in all groups. Behavioral tests were conducted during the light phase of the circadian cycle, between ages 2 and 5 months.

Object location memory. On day 1 , each mouse was placed in an empty white plastic chamber $\left(40 \times 40 \mathrm{~cm}^{2}\right)$ and allowed to explore for $30 \mathrm{~min}$ to habituate to the chamber. A vertical 
stripe of black duct tape was placed on one wall of the chamber to facilitate subsequent spatial memory. On day 2, the subject mouse was placed in the same empty arena for a second habituation session of $10 \mathrm{~min}$ duration. The mouse was removed, and two identical objects were placed in the chamber $\sim 12 \mathrm{~cm}$ from the wall and $\sim 18 \mathrm{~cm}$ apart. The mouse was then placed back into the chamber and allowed to explore the test arena containing the two identical objects for $10 \mathrm{~min}$. After this familiarization session, the subject mouse was removed from the arena and placed into an empty holding cage in a different room for $1 \mathrm{~h}$. Objects were cleaned in an Alconox bath and chambers were cleaned with ethanol between the familiarization and novel object recognition test sessions. One of the objects was replaced in its original location, and the other object was moved to a new location, $\sim 18 \mathrm{~cm}$ forward from its initial location. After the $1 \mathrm{~h}$ interval, the subject mouse was returned to the testing chamber and allowed to explore both objects for $5 \mathrm{~min}$. Time spent sniffing each object was recorded and scored by the Noldus Ethovision software. Object location memory was defined as spending significantly more time sniffing the relocated object than sniffing the object that remained in its original location. The novel object location was counterbalanced (left or right) to prevent side bias.

Male-female reciprocal social interactions and vocalizations. Adult 16p11.2 +/+ and B6 female mice in estrus were used as stimulus mice for adult male 16p11.2 deletion mice. Each female mouse was used as a partner for a maximum of three male subject mice. Each trial was run in a clean cage $\left(36.9 \times 15.6 \times 13.2 \mathrm{~cm}^{3}\right)$ with an $0.5 \mathrm{~cm}$ layer of bedding under dim red lighting in a sound-attenuating chamber. One female stimulus mouse and one male subject mouse were placed in the cage and behaviors were recorded with a video camera for $5 \mathrm{~min}$. Interactions were scored from videos by human observers blind to genotype and treatment, using the Noldus Observer XT 8.0 event recording software. Social parameters scored in the male subjects included nose-to-nose sniff (sniffing snout region of partner), nose-to-anogenital sniff (sniffing anogenital region of partner), and follow (walking closely behind partner). Ultrasonic vocalizations were recorded during the 5 min session using an ultrasonic microphone (Avisoft UltraSoundGate) inside the sound attenuating chamber and subsequently scored using Avisoft SASLab Pro.

General exploratory locomotion. To assess potential drug effects on general activity, locomotion was assessed during a 10 min exploration session in the same chambers used for the object location memory task. Total distance traveled was scored with the Noldus Ethovision software.

Statistical analysis. Object location memory data were analyzed using paired $t$-tests, comparing the number of seconds spent sniffing each object within genotype and within treatment, during the familiarization and novel object recognition phases, as previously described (Vogel-Ciernia and Wood, 2014). Male-female social interaction data were analyzed using an unpaired $t$-test, comparing treatments within genotype for each parameter. Locomotor activity data were analyzed using one-way analysis of variance followed by Tukey's multiple comparisons post hoc test. Body weight and daily consumption were analyzed using two-way repeated-measures analysis of variance.

\section{RESULTS}

Two independently generated $16 \mathrm{p} 11.2$ microdeletion model mice (termed 16p11.2 df/+) were employed in our studies. The Mills mice (Horev et al, 2011) were used for all studies conducted in the Bear laboratory at MIT and the Dolmetsch mice (Portmann et al, 2014) were used for all studies conducted in the Crawley laboratory at UCD. Before describing the effects of $R$-baclofen, here we briefly review the deficits that have been previously reported in these two lines of mice.

The Mills mice display poor survival as pups, smaller body weights, higher home cage activity, and an unusual descent from the cage ceiling in some individuals (Brunner et al, 2015; Horev et al, 2011). Normal sociability and preference for social novelty were observed in $16 \mathrm{p} 11.2 \mathrm{df} /+$ mice in the three-chambered social approach task, with no genotype differences detected on reciprocal social interactions or male sniffing and vocalizing in response to female urine (Brunner et al, 2015). Cognitive studies of the Mills mice revealed deficits in contextual fear conditioning, passive avoidance, and novel object recognition (Brunner et al, 2015; Pucilowska et al, 2015; Tian et al, 2015), while T-maze acquisition and reversal did not differ between genotypes (Brunner et al, 2015). Lower open field activity and anxietyrelated tendencies in the elevated plus-maze were reported in the Mills line (Pucilowska et al, 2015).

The Dolmetsch line of $16 \mathrm{p} 11.2$ deletion mice similarly displayed poor pup survival, with body weights significantly lower than wild-type littermates throughout life, while other measures of general health remained normal throughout the lifespan in the surviving heterozygotes (Portmann et al, 2014). Circling and jumping motor stereotypies were seen in a small subset of individuals (Portmann et al, 2014; Yang et al, 2015b). Social behaviors were normal on both threechambered social approach and juvenile reciprocal social interactions but reduced on parameters of male-female reciprocal social interactions and accompanying ultrasonic vocalizations, as compared with wild-type male littermate controls (Portmann et al, 2014; Yang et al, 2015b). Cognitive deficits were prominent in the Dolmetsch $16 \mathrm{p} 11.2 \mathrm{df} /+$ mice on recognition tasks, including novel object recognition, object location memory, preference for social novelty, and touchscreen pairwise visual discrimination acquisition and reversal (Portmann et al, 2014; Yang et al, 2015a). No differences between genotypes were detected on contextual fear conditioning; water maze could not be conducted owing to poor swimming abilities (Portmann et al, 2014; Yang et al, 2015a).

\section{MIT Studies on Mills Mice}

Object recognition. Using the Mills $16 \mathrm{p} 11.2$ deletion mice (Horev et al, 2011; Tian et al, 2015), we first examined the effects of chronic $R$-baclofen treatment using an object recognition memory task. Mice were allowed to explore an arena with two identical objects for two 10-min exploration 

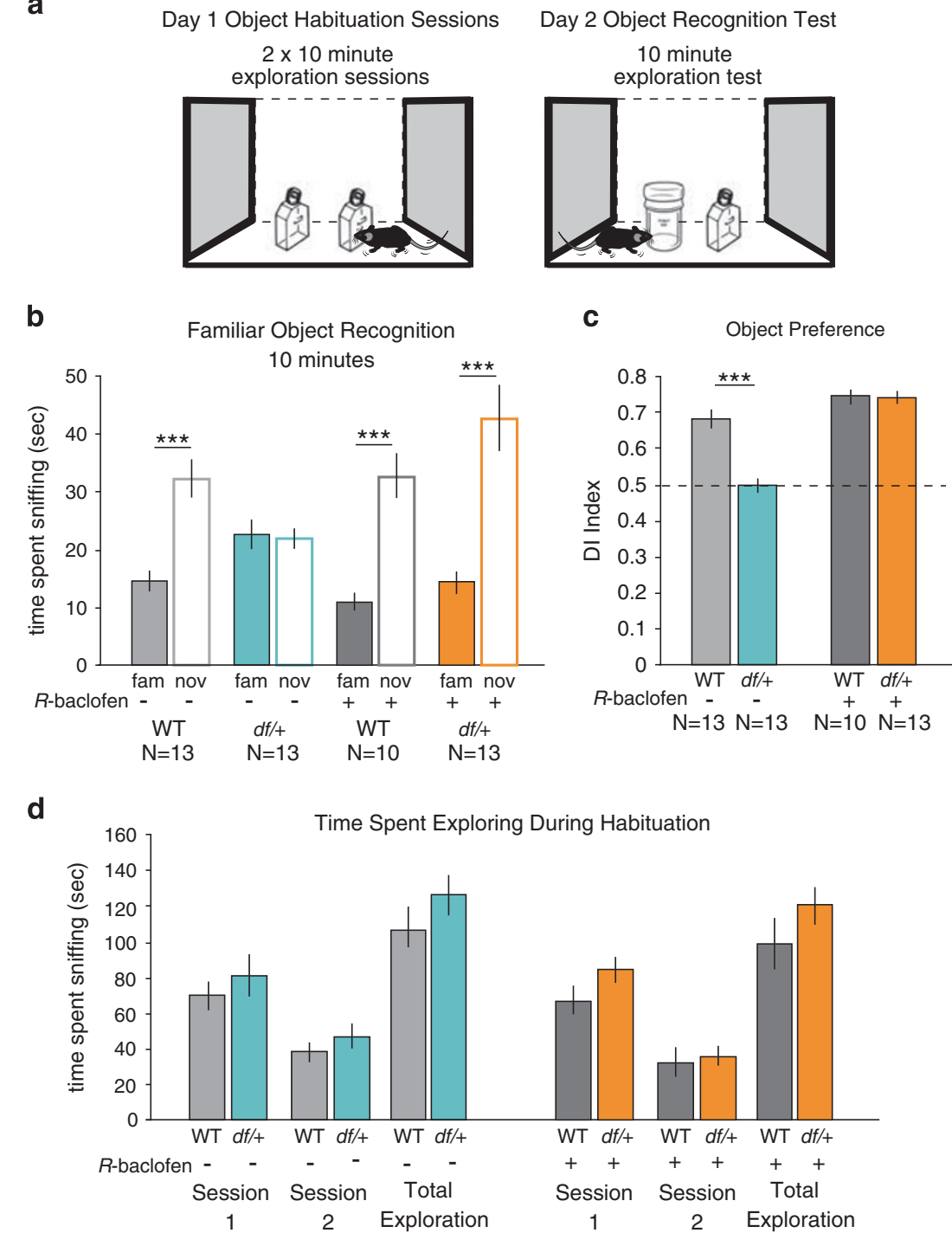

Figure I Chronic R-baclofen treatment restores novelty detection deficits in an object recognition task in I6p I I.2 df/+ mice. (a) Experimental design of novel object recognition task. (b) Vehicle-treated $16 \mathrm{p} \mid 1.2 \mathrm{dfl}+$ mice show impaired novelty detection on experimental test day 2 when presented with a familiar and novel object compared with vehicle-treated WT (WT veh, fam vs nov: $t(12)=6.5 \mathrm{I} ; p<0.00 \mathrm{I} ; \mathrm{df} /+$ veh, fam vs nov: $t(\mathrm{I})=0.467 ; p=0.649 ; \mathrm{WT}$ $R$-baclofen, fam vs nov: $t(9)=7.68$; $p<0.00 \mathrm{I}$; $\mathrm{df} /+\mathrm{R}$-baclofen, fam vs nov: $t(\mathrm{I})=6.54 ; p<0.00 \mathrm{I})$. (c) As depicted in panel (b), vehicle-treated I6p I I.2 dfI+ mice show no preference for the novel or familiar object, exploring each approximately equally, whereas WT mice treated animals favor the novel object, as determined by calculating discrimination index $(W T$, veh vs $f f /+$, veh: $t(24)=6.49 ; p<0.00 \mathrm{I}$ ). In comparison, similar to vehicle-treated $W T$ animals, R-baclofen-treated WT and $16 \mathrm{p} / \mathrm{I} .2 \mathrm{df} /+$ mice show significantly more exploration of a novel object compared with a familiar object, as depicted by a discrimination significantly $>0.5$. Chronic R-baclofen treatment restores novelty detection in $\mid 6 \mathrm{p} \mathrm{I} \mathrm{I.2} \mathrm{df/+} \mathrm{mice,} \mathrm{making} \mathrm{them} \mathrm{indistinguishable} \mathrm{from} \mathrm{WT} \mathrm{mice}$ (WT, R-baclofen vs $\mathrm{df} /+$, R-baclofen: $t(2 \mathrm{I})=0.063 ; p=0.950)$. Two-way ANOVA, genotype: $F=23.0, p<0.00 I$; treatment: $F=62.4, p<0.00 I$; genotype $\times$ treatment: $F(3,45)=22.2, p<0.00 \mathrm{I}$. (d) There is no significant difference in time spent exploring each of two identical objects during the first object habituation session in either genotype regardless of treatment nor is there any significant difference in total time spent exploring during either habituation session (WT veh vs $d f /+$ veh, session I: $t(24)=0.802, p=0.430 ; W T$ veh vs $d f /+$ veh, session $2: t(24)=1 . I 00, p=0.282 ;$ WT veh vs $d f /+$ veh, total: $t(24)=1.20, p=0.241$; WT R-baclofen vs $d f I+R$-baclofen, session $I: t(2 I)=1.84, p=0.079 ; W T R$-baclofen vs $d f I+R$-baclofen, session $2: t(2 I)=0.6 \mid 4$, $p=0.546$; WT R-baclofen vs $d f /+R$-baclofen, total: $t(21)=1.64, p=0.116)$. All data for all figures are plotted as mean $\pm S E M ; n$ indicates the number of animals. $* * * * * 0.00 I, R$-baclofen vs vehicle within genotype.

sessions, spaced $1-2 \mathrm{~h}$ apart. Twenty-four hours later, one of the familiar objects was replaced with a novel object and a discrimination index was calculated as (time spent sniffing the novel object)/(cumulative time spent sniffing the novel +familiar object) across a 10-min testing session (Figure 1a). Vehicle-treated WT mice showed a strong preference for the novel object. In comparison and similar to previous reports, vehicle-treated $16 \mathrm{p} 11.2 \mathrm{df} /+$ mice did not show a preference for the novel object, exploring the familiar and novel object equally (Figures $1 \mathrm{~b}$ and $\mathrm{c}$ ). Chronic treatment with $R$-baclofen had no effect on preference for a novel object in WT mice but completely restored novelty detection in $16 p 11.2 d f /+$ mice (Figures $1 b$ and c). To ensure that our findings were not confounded by differences in total overall exploration during the habituation sessions to the familiar object, we scored total sniffing during the two exploration 
sessions on day 1 and observed no differences across genotype or treatment (Figure 1d).

Context recognition. We next examined the effects of chronic $R$-baclofen administration on cognitive performance in an aversive hippocampus-associated context recognition task in the $16 \mathrm{p} 11.2 \mathrm{df} /+$ mice. In this assay, mice were exposed to a distinctive environmental context in which they receive a foot shock (The acute behavioral response to foot shock in the Mills 16p11.2 df/+ mice was previously shown to be no different from WT (Tian et al, 2015), suggesting comparable sensory sensitivity.). Twenty-four hours later, the mice were returned to either the same (familiar) or a different (novel) context on the testing day (Figure 2a). Confirming previous observations, vehicle-treated $16 \mathrm{p} 11.2$ $d f /+$ mice exhibited profound memory deficits on the testing day, as evidenced by lack of freezing in the familiar context where they had previously received a foot shock (Figure $2 \mathrm{~b}$ ). $16 \mathrm{p} 11.2 \mathrm{df} /+$ mice treated with $R$-baclofen froze significantly more in the familiar context on testing day, comparable to WT mice treated with either vehicle or $R$-baclofen, demonstrating that the drug treatment restored the ability to both acquire and recall the association between context and an aversive event (Figure 2b).

Open field habituation. In order to investigate habituation to a context, we tracked the activity of the $16 \mathrm{p} 11.2 \mathrm{df} /+$ mice across two 15-min recording sessions, spaced 1-2 $\mathrm{h}$ apart. During each habituation session, we used the Cineplex monitoring software to monitor activity throughout a $40 \times 40 \mathrm{~cm}^{2}$ environment. We used MATLAB to analyze the time spent in two predefined zones (outer, inner) of the behavior arena across sessions (Figure 3a). We first measured the total distance (pooled across sessions) traveled by WT and $16 \mathrm{p} 11.2 \mathrm{df} /+$ mice as an indicator of hyperactivity. Vehicle-treated $16 \mathrm{p} 11.2$ heterozygous mice a
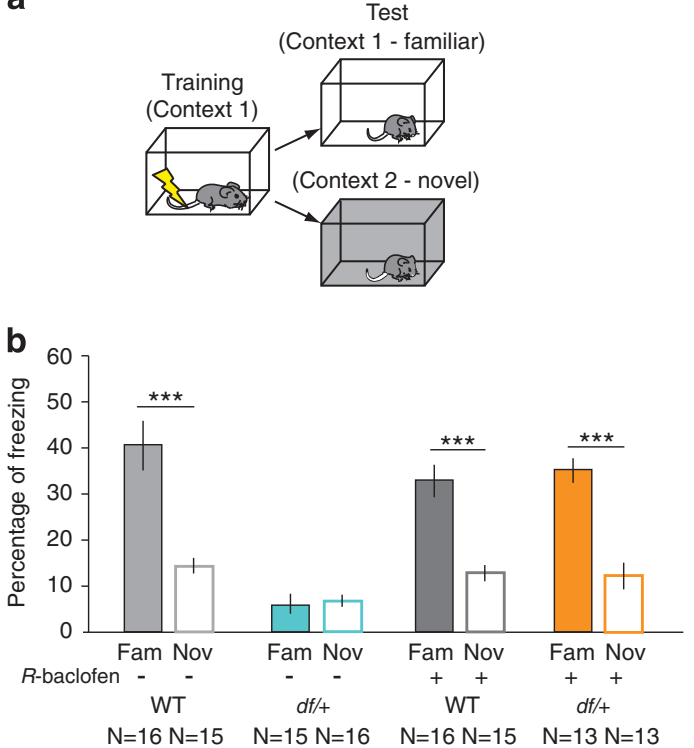

Figure 2 Chronic R-baclofen treatment restores memory deficits in a context-dependent aversive learning task in $|6 \mathrm{p}| 1.2 \mathrm{df} \mid+$ mice. (a) Experimental design of context-dependent discrimination task. (b) Vehicletreated $|6 \mathrm{p}| 1.2 \mathrm{df} /+$ mice show no difference in freezing in the familiar vs novel context and significantly less freezing in the familiar context compared with WT mice ( $d f l+$ veh, nov vs fam: $t(29)=0.227, p=0.822 ; W T$, veh vs $d f /+$, veh: $t(29)=7.05, p<0.00 I)$. Vehicle- and $R$-baclofen-treated WT mice are able to distinguish a novel from familiar context (WT veh, nov vs fam: $t(29)=5.70, p<0.00$ I; WT R-baclofen, nov vs fam: $t(28)=5.29, p<0.00$ I). Upon chronic treatment with $R$-baclofen, $|6 \mathrm{p}| \mathrm{l} .2 \mathrm{df} \mid+$ mice are able to distinguish a novel from familiar context as indicated by significantly increased freezing in the familiar context compared with novel context $(d f l+R$-baclofen, nov vs fam: $t(24)=6.03, p<0.00 I)$. Three-way ANOVA, genotype: $F=30.7, p<0.001$; treatment: $F=7.86, p<0.01$; context: $\mathrm{F}=82.0, p<0.00 \mathrm{I}$; genotype $\times$ treatment: $\mathrm{F}=22.2, p<0.00 \mathrm{I}$; genotype $\times$ context: $F=\mid 1.5, \quad p<0.00 I$; treatment $\times$ context: $F=3.01, \quad p=0.086$; genotype $\times$ treatment $\times$ context: $F(7, I \mid I)=17.7, p<0.00 I)$. **** $p<0.001$, $R$-baclofen vs vehicle within genotype.

Figure $316 \mathrm{p} \mid 1.2 \mathrm{dfl+}$ mice show habituation deficits in an open field task, which is reversed by chronic R-baclofen treatment. (a) Experimental design of open field habituation task. (b) $|6 \mathrm{p}| \mathrm{I} .2 \mathrm{df} /+$ mice treated with vehicle show statistically significant hyperactivity compared with WT animals treated with vehicle in the open field as indicated by distance traveled over the course of both habituation sessions (veh vs $d f l+v e h: t(22)=4.33, p<0.00 \mathrm{I}$ ). WT animals treated with $R$-baclofen show significantly increased locomotion compared with vehicle-treated animals (WT veh vs $R$-baclofen: $t(22)=2.89, p<0.01$ ). There is no statistical significance between: $|6 p| \mid .2 \mathrm{df} /+$ animals treated with vehicle or $R$-baclofen ( $\mathrm{df} /+$ veh vs $R$-baclofen: $t(22)=0.248, p=0.807 ; \mathrm{WT}$ ); WT animals treated with R-baclofen and I6p I I.2 heterozygous animals treated with vehicle (dfI+ veh vs WT R-baclofen: $t(22)=0.0$ I0, $p=0.992)$ or WT animals and $|6 p| \mid .2$ heterozygous treated with $R$-baclofen (WT R-baclofen vs $d f /+R$-baclofen: $t(22)=0.206, p=0.839$ ). (c) Across genotypes and treatments, animals travel a greater distance in the first habituation session compared with the second habituation session (WT veh, session I vs session 2: $t(1)$ I) $=6.85$, $p<0.001$; $d f I+$ veh, session I vs session 2: $t(\mathrm{I} I)=9.58, p<0.00 \mathrm{I}$; WT R-baclofen, session I vs session 2: $t(\mathrm{I} I)=4.8 \mathrm{I}, p<0.00 \mathrm{I}$; $d f \mid+R$-baclofen, session I vs session 2: $t(I \mid)=4.56, p<0.00 I$. (d) Vehicle-treated WT and I $6 \mathrm{pl}$ I .2 $\mathrm{df} /+$ mice exhibit similar behavior during the first habituation session. During the second session, WT mice spend significantly more time in the outer zone of the arena, whereas $16 \mathrm{pl} \mid .2 \mathrm{dfl+}$ mice do not spend significantly more time in either the inner or outer zones of the arena (WT vs $d f l+$, Session I-outer zone, $t(22)=1.32, p=0.201$; WT vs $d f l+$, Session I-inner zone, $t(22)=1.32$, $p=0.201$; $W T$ vs $d f l+$, Session 2-outer zone, $t(22)=5.83, p<0.00 \mathrm{I}$; WT vs $d f /+$, Session 2 -inner zone, $t(22)=5.83, p<0.00 \mathrm{I}$; WT, Session I, inner vs outer, $t(\mathrm{I} I)=0.782$, $p=0.450 ; d f /+$, Session I, inner vs outer, $t(I)=1.13, p=0.28 I$; WT, Session 2, inner vs outer, $t(1 \mid)=9.90, p<0.001$; $d f /+$, Session 2, inner vs outer, $t(I I)=0.820, p=0.430)$. Three-way genotype $\times$ zone $\times$ session: $F(7,88)=16.867, p<0.00 I)$. Pairwise multiple comparison procedures (Holm-Sidak method): genotype within session I, WT vs $f f I+: t=0.00005, p=1.00$; zone within session I, inner vs outer: $t=0.131, p=0.896$; genotype within innersession 2, WT vs $d f l+: t=5.82, p<0.00$ l; genotype within outer-session 2, WT vs $d f l+: t=5.82, p<0.001$; zone within WT, session 2: $t=12.9$, $p<0.001$; zone within $\mathrm{df} / \mathrm{t}$, session $2: t=1.24, p=0.2 \mid 8$. (e) R-baclofen-treated WT and $|6 \mathrm{p}| \mathrm{I} .2 \mathrm{df} \mid+$ mice exhibit similar behavior during the first habituation session. During the second session, both WT mice and $16 \mathrm{p} \mid 1.2 \mathrm{df} /+$ mice spend significantly more time in the outer zone of the arena (WT vs $\mathrm{df} /+$, session I-outer zone, $t(22)=0.142, p=0.889$; WT vs $d f /+$, session I -inner zone, $t(22)=0.142, p=0.889 ; W T$ vs $d f /+$, session 2 -outer zone, $t(22)=0.106, p=0.9 \mid 7 ;$; vs $d f \mid+$, session 2-inner zone, $t(22)=0.106, p=0.917$; WT, Session I, inner vs outer, $t(I \mid)=1.21, p=0.252$; $d f \mid+$, Session I, inner vs outer, $t(I I)=1.60$, $p=0.138 ; W T$, Session 2, inner vs outer, $t(I)=2.56, p=0.026 ; d f l+$, Session 2 , inner vs outer, $t(I I)=3.19, p<0.01$ ). Three-way genotype $\times$ zone $\times$ session: $F(7,88)=0.055, p=0.8 \mid 4)$. (f) Dolmetsch $|6 p| \mid .2 \mathrm{df} /+$ mice in UCD lab: Total distance traveled was recorded using the Noldus Ethovision software. No significant effect of drug treatment was detected on exploratory activity during a 10-min open field session in the same chambers used for the object location memory task. One-way ANOVA $(F(3,8 \mathrm{I})=3.22 ; p=0.027$, Tukey's multiple comparison test $p=0.027$ for the comparison of WT vehicle vs df/+ vehicle only. ${ }^{*} p<0.05$, ** $p<0.01$, **** $p<0.001$, R-baclofen vs vehicle within genotype. 
traveled a significantly greater distance in the arena compared with vehicle-treated WT mice across both habituation sessions, indicative of a generalized hyperactivity in these mice. Chronic administration of $R$-baclofen had no effect on locomotion in $16 \mathrm{p} 11.2 \mathrm{df} /+$ but rather surprisingly induced hyperactivity in WT mice to a degree comparable to the treated and untreated 16p11.2 df/+ mice (Figure 3b).

Across all genotypes and treatments, mice spent more time exploring the context during the first recording session compared with the second session (Figure 3c). Zone-specific analysis revealed that vehicle-treated WT and 16p11.2 df/+ mice explored the inner and outer zone of the environment roughly equally during the first $15-$ min session. However, vehicle-treated WT mice spend significantly more time near the walls in the outer zone of the arena during the second 15min session, whereas $16 \mathrm{p} 11.2 \mathrm{df} /+$ mice spend roughly equal time exploring the outer and inner zones of the arena during the second session, potentially reflecting a context recognition deficit across sessions in these mice (Figure $3 \mathrm{~d}$ ). Interestingly, chronic $R$-baclofen administration does not affect exploration patterns of WT mice but restores normal exploration in $16 \mathrm{p} 11.2 \mathrm{df} /+$ mice, leading to increased time spent in the outer zone and decreased time spent exploring the inner zones in the second exploration session (Figure $3 \mathrm{e}$ ).

\section{UCD Studies on Dolmetsch Mice}

Locomotor activity. Exploratory activity was tested in a standard open field to evaluate potential sedative effects of

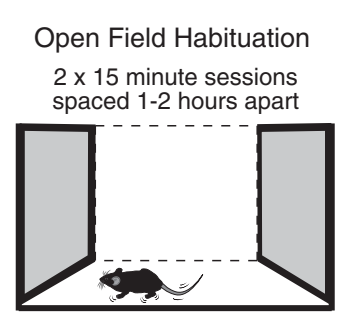

C

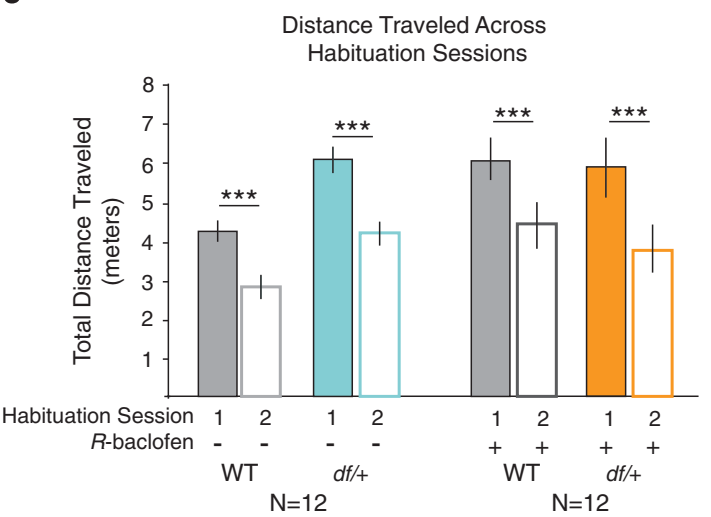

e

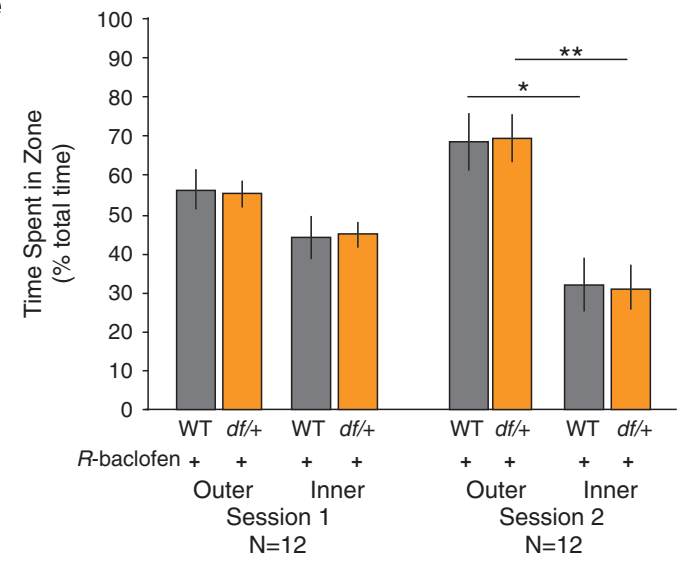

b
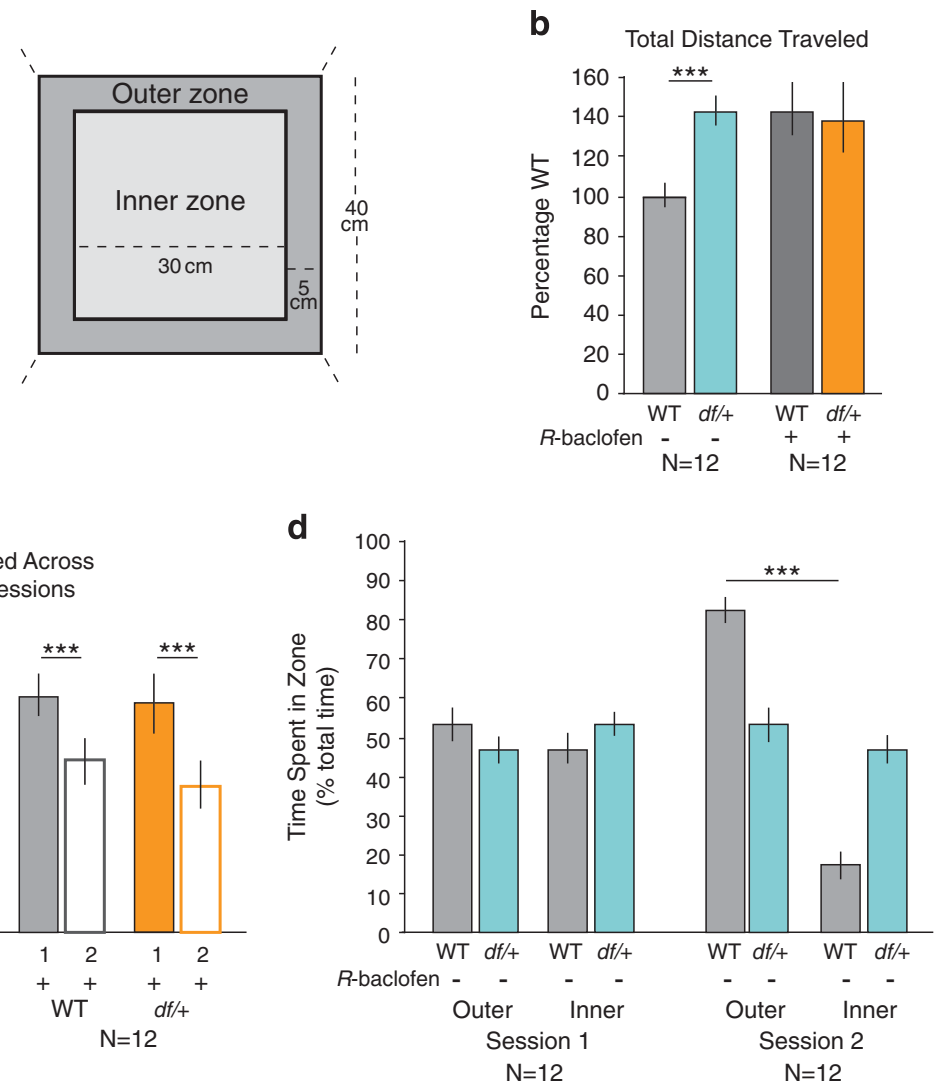

f

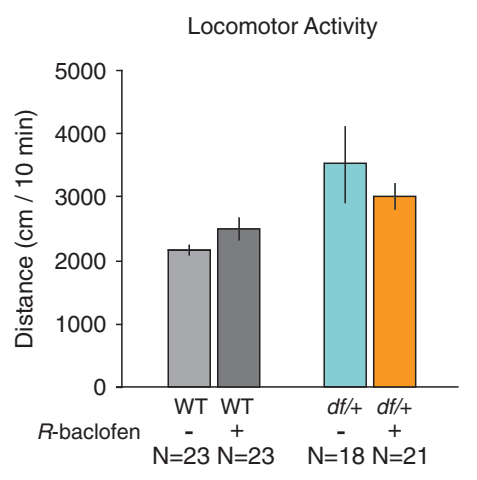


$R$-baclofen. Consistent with studies on Mills mice, treatment did not significantly affect open field locomotor activity in WT or 16p11.2 df/+ Dolmetsh mice at the dose employed in these studies (Figure 3f).

Object location memory. During the familiarization phase of the object location memory assay, no innate side bias for object position was detected in mice of either genotype treated with vehicle or $R$-baclofen (Figure $4 \mathrm{a}$ ). During the object location test phase, WT mice administered vehicle spent significantly more time sniffing the object in the novel location compared with time spent sniffing the object in the familiar location (Figure $4 \mathrm{~b}$ ). $16 \mathrm{p} 11.2 \mathrm{df} /+$ mice administered vehicle did not exhibit significant object location memory, but 16 p11.2 $d f /+$ mice administered $R$-baclofen spent significantly more time sniffing the object in the novel location compared with the object in the familiar location. WT mice administered $R$-baclofen displayed increased exploration of both objects but interestingly did not display object location memory, a finding to be further investigated in future studies.

Male-female reciprocal social interactions and vocalizations. Lower scores in 16p11.2 deletion males interacting with estrous females were significantly ameliorated by $R$ baclofen treatment on several parameters (Figure 5). 16p11.2 $d f /+$ males administered $R$-baclofen showed significantly greater nose-to-anogenital sniffing as compared with vehicle treatment (Figures $5 \mathrm{c}$ and $\mathrm{d}$ ). Time spent following was also higher in $16 \mathrm{p} 11.2 \mathrm{df} /+$ mice that received $R$-baclofen as compared with vehicle (Figures $5 \mathrm{e}$ and $\mathrm{f}$ ). Interestingly, $R$ baclofen significantly decreased these social behaviors in the wild types. $R$-baclofen had no significant effect on nose-tonose sniffing in $16 \mathrm{p} 11.2$ deletion males but significantly decreased nose-nose sniffing in WT males (Figure 5a). $R$ baclofen also had no effect on the number of ultrasonic vocalizations emitted by $16 \mathrm{p} 11.2 \mathrm{df} /+$ males but significantly reduced the number of ultrasonic vocalizations in wild type (Figure 5g).

\section{DISCUSSION}

$16 \mathrm{p} 11.2$ deletion syndrome includes symptoms of intellectual impairment and autism (Zufferey et al, 2012). Cognitive and social deficits were previously detected in three independently generated lines of $16 \mathrm{p} 11.2$ deletion mice (Arbogast et al, 2016; Brunner et al, 2015; Portmann et al, 2014; Pucilowska et al, 2015; Tian et al, 2015; Yang et al, 2015a,b). We employed two of these lines to test the hypothesis that the $\mathrm{GABA}_{\mathrm{B}}$ agonist $R$-baclofen could improve performance in behavioral domains relevant to symptoms of the human 16p11.2 deletion syndrome. Our two separate laboratories used the same $R$-baclofen dose and treatment time course to test $16 \mathrm{p} 11.2$ deletion mice and their wild-type littermates on distinct but complementary behavioral assays. This parallel, corroborative approach was undertaken to maximize rigor and reproducibility in evaluating the efficacy of a drug treatment in preclinical studies.

\section{Chronic R-Baclofen Treatment Corrects Several Cognitive Defects in 16p11.2 df/+ Mice}

Impaired novelty detection in the two assays used here, object recognition and object location memory, is one of the most robust and reproducible phenotypes associated with all three current 16p11.2 heterozygous deletion mouse models. Similar to previous studies, we found profound deficits in both novel object recognition and object location memory in the Mills and Dolmetsch mouse lines, respectively (Brunner et al, 2015; Pucilowska et al, 2015). Chronic administration of $R$-baclofen significantly improved novelty detection in both $16 \mathrm{p} 11.2 \mathrm{df} /+$ mice mouse models in these recognition memory tasks. Furthermore, in the Mills 16p11.2 df/+ mouse model, chronic $R$-baclofen treatment also corrected severely impaired context discrimination.

It was reported previously that open field locomotor behavior fails to habituate in the Mills 16p11.2 df/+ mice over the course of 15 min (Pucilowska et al, 2015). By comparing the locomotion of $16 \mathrm{p} 11.2 \mathrm{df} /+$ mice and wild-type littermates across two 15-min open field habituation sessions spaced $1-2 \mathrm{~h}$ apart, we were also able to identify an additional behavioral deficit in the Mills mouse line. Wild-type mice spent less time in the center of the environment during the second recording session, exhibiting characteristic thigmotaxic behavior. In contrast, the activity of $16 \mathrm{p} 11.2 \mathrm{df} /+$ mice was indistinguishable between recording sessions. This difference may represent a deficit in recognition of a familiar environment, although we acknowledge that there could be multiple interpretations of the findings, such as increased impulsivity or decreased anxiety. Nevertheless, regardless of the interpretation, 16p11.2 heterozygous mice treated with chronic $R$-baclofen exhibited behavior that was virtually indistinguishable from wild-type mice treated with either vehicle or $R$-baclofen.

\section{Chronic $R$-Baclofen Improves Social Behaviors in $16 \mathrm{p} 11.2 \mathrm{df} /+$ mice}

We previously reported reduced reciprocal social interactions by male $16 \mathrm{p} 11.2 d f /+$ mice on parameters of anogenital sniffing and following an estrous female, along with fewer ultrasonic vocalizations during the social session (Yang et al, 2015b). Here we replicated the social and vocalization phenotypes during male-female interactions and detected elevations of anogenital sniffing and following in 16p11.2 deletion males treated with $R$ baclofen, while vocalizations remained low.

\section{Effects of $\boldsymbol{R}$-Baclofen on Locomotor Activity}

Neither laboratory observed any improvement in the hyperlocomotion exhibited by the $16 \mathrm{p} 11.2 \mathrm{df} /+$ mice with chronic $R$-baclofen administration. In fact, the Bear (but not Crawley) laboratory observed a paradoxical increase in locomotion in treated wild-type mice. Although at high doses $R$-baclofen is known to induce a sedative effect in humans and mice (Henderson et al, 2012), this clearly was not observed in our studies at the dose regimen employed. The fact that such a dramatic improvement in cognition, along with improvement in two parameters of social behavior, is observed at doses that fail to cause sedation suggests that $R$-baclofen has a broad therapeutic window. On the other hand, the finding that the hyperlocomotion and vocalization phenotypes were not 

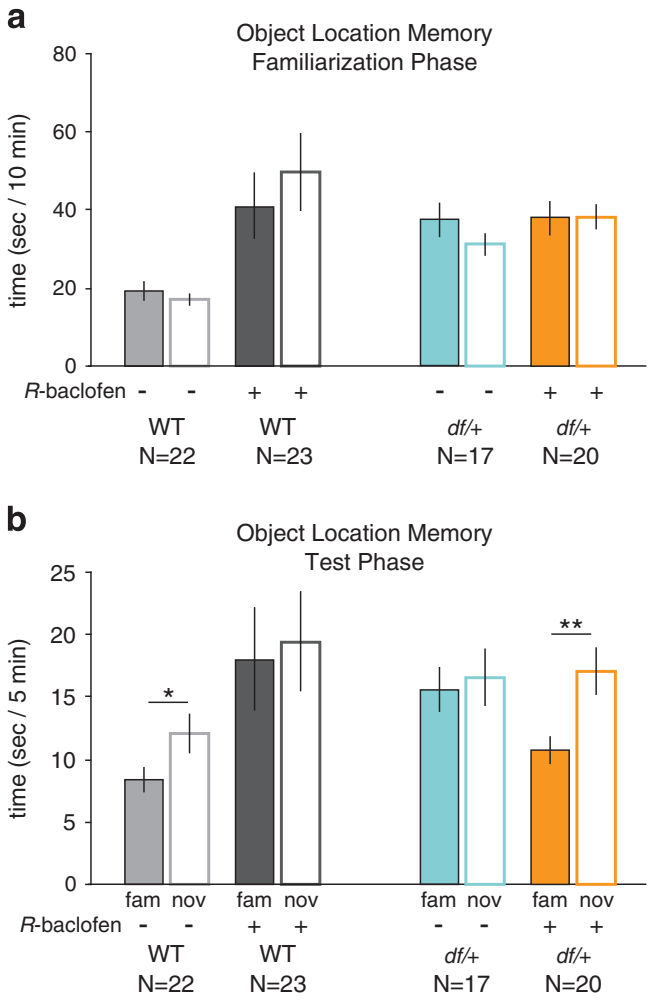

Figure $4 \quad|6 p| \mid .2 d f /+$ mice displayed a learning and memory deficit in object location memory, which was reversed by $R$-baclofen treatment. $R$ baclofen $(0.5 \mathrm{mg} / \mathrm{ml})$, indicated by '+', rescued the deficit in object location memory in $|6 p| 1.2 \mathrm{df} /+$ mice. (a) During the familiarization phase, no side bias was detected $(\mathrm{WT}$, veh: $t(2 \mathrm{I})=0.864 ; p=0.398$, NS; $\mathrm{df} / \mathrm{t}$, veh: $t(16)=1.31 ; p=0.208$, NS; WT, R-baclofen: $t(22)=1.97 ; p=0.062, \mathrm{NS} ; \mathrm{df} \mid$ + , R-baclofen: $t(19)=0.00 \mathrm{I}, p=0.995$, NS). (b) During the test phase, WT mice administered vehicle, indicated by ' - ', spent significantly more time sniffing the object in the novel location (Nov) compared with time spent sniffing the object in the familiar location (Fam), while $|6 \mathrm{p}| 1.2 \mathrm{df} /+$ mice administered vehicle did not exhibit significant object location memory (WT, veh: $t(2 \mid)=2.34 ; p=0.029 ; d f /+$, veh: $t(\mid 6)=0.305 ; p=0.764$, NS). $|6 p|$ |.2 df/+ mice administered R-baclofen spent significantly more time sniffing the object in the novel location compared with the object in the familiar location ( $d f /+$, R-baclofen $t(19)=3.00, p<0.0 I)$. WT administered $R$-baclofen increased exploration of both objects and did not display the expected object location memory (WT, R-baclofen $t(22)=0.641$; $p=0.528) . * p<0.05, * * p<0.01, R$-baclofen vs vehicle within genotype.

improved by our treatment indicates that not all aberrant behavioral phenotypes associated with $16 \mathrm{p} 11.2$ deletion mice respond to this treatment.

\section{Mechanism of Action}

At this point, we can only speculate how $R$-baclofen treatment improves cognitive and social phenotypes in adult $16 \mathrm{p} 11.2 \mathrm{df} /+$ mice. Our experiments were motivated in part by an earlier study in which we found a synaptic phenotype in the hippocampus that resembles what is observed in the $F m r 1^{-/ y}$ mice. Specifically, the data showed that $16 \mathrm{p} 11.2$ $d f /+$ mice also have aberrant activity-dependent protein synthesis regulation downstream of mGluR5 and increased hippocampal expression of Arc protein, a molecular marker of elevated neuronal activity. Moreover, as in the $F m r 1^{-/ y}$ mice, impairments in hippocampus-dependent fear memory could be ameliorated by treatment with an mGluR5-selective negative allosteric modulator (NAM) (Tian et al, 2015). In fragile $\mathrm{X}, R$-baclofen was advanced as a treatment because it can also normalize protein synthesis (Henderson et al, 2012; Qin et al, 2015), presumably by inhibiting glutamate release. An additional motivation for our experiments in $16 \mathrm{p} 11.2$ $d f /+$ mice was the previous finding that $R$-baclofen treatment can also improve sociability and repetitive behaviors in two additional mouse models of autism, the BTBR and C58 inbred strains (Silverman et al, 2015). BTBR mice have reduced GABAergic neurotransmission (Gogolla et al, 2014; Han et al, 2014), and deficits in both strains also are improved by treatment with an mGluR5 NAM (Silverman et al, 2012).

As a working hypothesis, we suggest that some cognitive and social deficits in 16p11.2 deletion mice arise from an ongoing disturbance in neuronal protein synthesis regulation that can be ameliorated with chronic drug treatment in adults. Two genes in the $16 \mathrm{p} 11.2$ region, MAPK3 and Major Vault Protein (MVP), are directly involved in signaling pathways downstream of mGlu5 signaling, and several other genes in this region are targets of FMRP (Crepel et al, 2011; Kolli et al, 2004; Paspalas et al, 2008). MAPK3 codes for ERK1, a key regulator of mGluR5-dependent protein synthesis, and levels of ERK1, ERK1 phosphorylation, and basal protein synthesis are reduced in the Mills $16 \mathrm{p} 11.2 \mathrm{df} /+$ mice (Tian et al, 2015). We note that baclofen, in addition to inhibiting presynaptic glutamate release, can stimulate ERK1/2 phosphorylation in hippocampal neurons by activation of dendritic $\mathrm{GABA}_{\mathrm{B}}$ receptors (Vanhoose et al, 2002). Conversely, MVP is thought to be a negative regulator of ERK1/2 (Kolli et al, 2004), and a rare inherited deletion in the $16 \mathrm{p} 11.2$ region confined to MVP, CDIPT1, SEZ6L2, ASPHD1, and KCTD13 has been shown to be associated with ASD (Crepel et al, 2011). More work is necessary to delineate how 16p11.2 microdeletion causes cognitive and social deficits and understand how these impairments can be reversed by $\mathrm{GABA}_{\mathrm{B}}$ receptor activation.

\section{Clinical Implications}

Our findings that $R$-baclofen improved performance on three cognitive tasks and reversed deficits on two measures of male-female reciprocal social interactions suggest the drug may have therapeutic utility in humans with $16 \mathrm{p} 11.2$ microdeletion syndrome. Racemic baclofen has been used clinically for many years for the treatment of spasticity in children and adults with cerebral palsy, and placebocontrolled trials in fragile $\mathrm{X}$ and autism using $R$-baclofen have shown that the drug is safe and well tolerated in patients with other developmental brain disorders.

Prior to the current study, the strongest preclinical rationale for use of $R$-baclofen for autism and ID derived from work in fragile X. However, despite promising findings in mice (Henderson et al, 2012; Qin et al, 2015), three placebo-controlled clinical trials failed to show any significant improvements using the predetermined metrics chosen as the primary end points, various subscales of the Aberrant Behavior Checklist (ABC) (Berry-Kravis et al, 2017b; BerryKravis et al, 2012). Nevertheless, efficacy was suggested by improvements in physician-rated global assessments and several secondary end points that included other ABC subscales. Notably, and regrettably, cognition was not 
a

Male-Female Social Interaction Nose-to-Nose Sniffing Duration

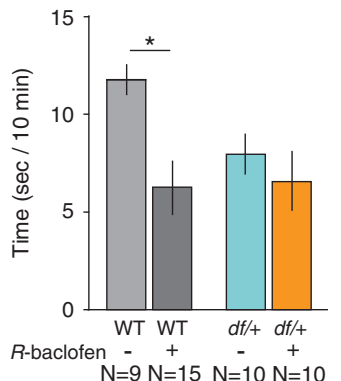

Male-Female Social Interaction Nose-to-Anogenital Sniffing Duration

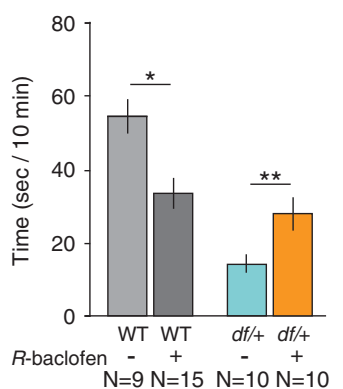

Male-Female Social Interaction Nose-to-Nose Sniffing Bouts

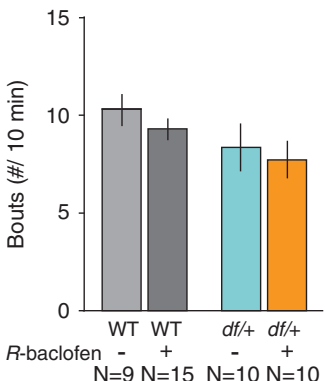

d

Male-Female Social Interaction Nose-to-Anogenital Sniffing Bouts

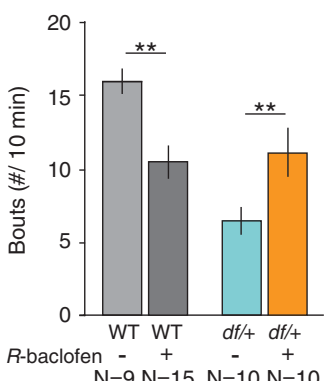

e

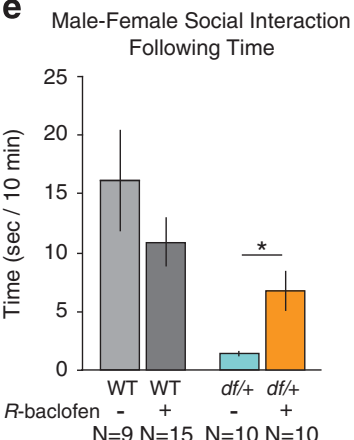

f

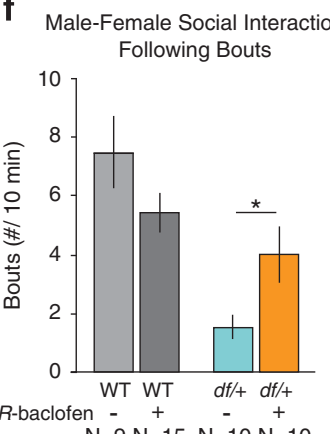

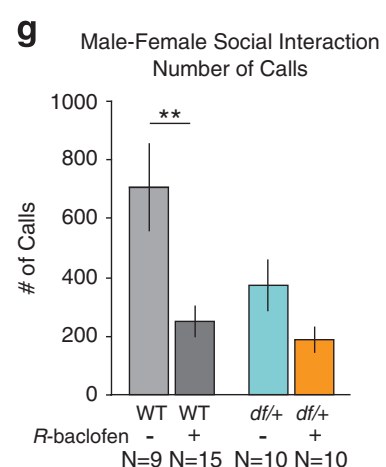

Figure 5 I $6 \mathrm{p} \mid$ | $.2 \mathrm{dfl} /$ male mice displayed lower scores on some parameters of male - female social interactions, which were reversed by R-baclofen treatment. Male $|6 \mathrm{p}| \mid .2 \mathrm{df} /+$ mice engaged in less reciprocal social interactions with an estrous female on some parameters, as compared with wild-type littermate controls. R-baclofen increased sociability in $16 \mathrm{p} \mathrm{I} \mathrm{I.2} \mathrm{df/+} \mathrm{male} \mathrm{mice.} \mathrm{Although} \mathrm{R-baclofen} \mathrm{did} \mathrm{not} \mathrm{significantly} \mathrm{affect} \mathrm{nose-to-nose} \mathrm{sniffing} \mathrm{in} \mathrm{I6p} \mathrm{I} \mathrm{I.2}$ $d f /+$ mice $(a, b: d f / t: t(18)=0.129 ; p=0.899$, NS; WT: $t(22)=2.12 ; p<0.05)$, R-baclofen treatment significantly increased nose-to-anogenital sniffing in $|6 p||.2 \mathrm{df}|+$ mice on measures of time spent $(\mathrm{c}: \mathrm{df} / \mathrm{t}: t(\mid 8)=2.14 ; p<0.05, \mathrm{WT}: t(22)=0.9|3, p=0.37|$, NS) and number of bouts $(\mathrm{d}: \mathrm{df} \mid+: t(22)=2.94$, $p<0.01$; WT: $t(\mid 8)=1 . \mid 2, p<0.05)$ and on time spent following the female (e: $d f \mid+: t(\mid 8)=2.66, p<0.05 ; W T: t(22)=1.16$; $p=0.260$, NS) and the number of following bouts (f: $\mathrm{df} / \mathrm{t}: \mathrm{t}(\mathrm{I})=2.15, p<0.05$; WT: $t(22)=1.52, p=0.143$, NS). (g) R-baclofen had no effect on the number of ultrasonic vocalizations emitted by $|6 \mathrm{p}| \mathrm{I} .2 \mathrm{df} / \mathrm{I}$ males $(t(\mathrm{I})=1.56, p=0.134$; NS)) but significantly reduced the number of ultrasonic vocalizations in $\mathrm{WT}(t(22)=2.87$; $p<0.0 \mathrm{I}$ ). Decreased scores appeared in WT treated with $R$-baclofen on measures of time spent in nose-to-nose sniffing, nose-to-anogenital sniffing, and the number of vocalizations, for unknown reasons, which do not appear to include sedation. ${ }^{*} p<0.05$, ${ }^{*} p<0.01$, $R$-baclofen vs vehicle within genotype.

assessed in these studies. These findings illustrate one of the great challenges in translational neuroscience-because the effects of a particular gene mutation do not manifest behaviorally the same in all individuals, improvements can be difficult to capture across the patient population in any single symptom domain. The same genetic disruption does not always cause the same symptoms (eg, autism in fragile $\mathrm{X}$ ), and the same symptoms may be caused by many different gene disruptions (eg, autism in the general population).

16p11.2 copy number variation was originally discovered in studies of autistic patients (Sebat et al, 2007; Weiss et al,
2008). Subsequent studies revealed variable penetrance of autistic phenotypes in deletion carriers but consistent deficits overall in traits related to adaptive skills (Zufferey et al, 2012). Full-scale intelligence quotient was reported to be $\sim 2$ SD lower, on average, in carriers compared with unaffected relatives, with $20 \%$ satisfying criteria for a DSM-IV diagnosis of ID (IQ $<70)$. To the extent that preclinical phenotypic improvements in mice can be used to guide end point and patient selection in humans, our findings-obtained in two independent laboratories in different 16p11.2 deletion mouse strains-suggest that $R$-baclofen should be explored for the treatment of cognitive phenotypes in affected humans. 


\section{FUNDING AND DISCLOSURE}

This work was supported by R01-MH106469 to MFB, T32 MH074249 to LJS, T32-MH073124 to TMK, and R01NS085709 and U54HD079125 to JNC. R-baclofen was supplied by the Simons Foundation Autism Research Initiative. Over the past 3 years, MFB has served as a consultant for and received compensation from BioAxone and Q-State Biosciences, Cydan, Fulcrum Therapeutics, Vertex, and Amgen. The other authors declare no conflict of interest.

\section{ACKNOWLEDGMENTS}

We thank J Joseph for technical assistance.

\section{REFERENCES}

Arbogast T, Ouagazzal AM, Chevalier C, Kopanitsa M, Afinowi N, Migliavacca E et al (2016). Reciprocal effects on neurocognitive and metabolic phenotypes in mouse models of $16 \mathrm{p} 11.2$ deletion and duplication syndromes. PLoS Genet 12: e1005709.

Auerbach BD, Osterweil EK, Bear MF (2011). Mutations causing syndromic autism define an axis of synaptic pathophysiology. Nature 480: 63-68.

Barnes SA, Wijetunge LS, Jackson AD, Katsanevaki D, Osterweil EK, Komiyama NH et al (2015). Convergence of hippocampal pathophysiology in Syngap+/- and Fmr1-/y mice. J Neurosci 35: 15073-15081.

Bear MF, Huber KM, Warren ST (2004). The mGluR theory of fragile X mental retardation. Trends Neurosci 27: 370-377.

Bernier R, Hudac CM, Chen Q, Zeng C, Wallace AS, Gerdts J et al (2017). Developmental trajectories for young children with 16p11.2 copy number variation. Am J Med Genet B Neuropsychiatr Genet 174: 367-380.

Berry-Kravis E, Hagerman R, Visootsak J, Budimirovic D, Kaufmann WE, Cherubini $M$ et al (2017a). Arbaclofen in fragile $\mathrm{X}$ syndrome: results of phase 3 trials. J Neurodev Disord 9: 3 .

Berry-Kravis EM, Hagerman RJ, Visootsak J, Budimirovic D, Kaufmann WE, Cherubini M et al (2017b). Arbaclofen in fragile $\mathrm{X}$ syndrome: results of phase 3 trials. J Neurodev Disord 9: 3 .

Berry-Kravis EM, Hessl D, Rathmell B, Zarevics P, Cherubini M, Walton-Bowen K et al (2012). Effects of STX209 (arbaclofen) on neurobehavioral function in children and adults with fragile $\mathrm{X}$ syndrome: a randomized, controlled, phase 2 trial. Sci Transl Med 4: 152 ra127.

Berry-Kravis EM, Lindemann L, Jønch AE, Apostol G, Bear MF, Carpenter RL et al (2017c). Drug development for fragile $\mathrm{X}$ syndrome: Lessons learned and implications for treatment of neurodevelopmental disorders. Nat Rev Drug Discov (in press).

Brunner D, Kabitzke P, He D, Cox K, Thiede L, Hanania T et al (2015). Comprehensive analysis of the 16p11.2 deletion and null Cntnap2 mouse models of autism spectrum disorder. PLOS ONE 10: e0134572.

Crepel A, Steyaert J, De la Marche W, De Wolf V, Fryns JP, Noens I et al (2011). Narrowing the critical deletion region for autism spectrum disorders on 16p11.2. Am J Med Genet B Neuropsychiatr Genet 156: 243-245.

Dhame SC, Silverman JL, Super CE, Lammers SHT, Hameed MQ, Modi ME et al (2017). Replicable in vivo physiological and behavioral phenotypes of the Shank3B null mutant mouse model of autism. Mol Autism 8: 26.

Dolen G, Osterweil E, Rao BS, Smith GB, Auerbach BD, Chattarji S et al (2007). Correction of fragile X syndrome in mice. Neuron 56: 955-962.
Ehninger D, Han S, Shilyansky C, Zhou Y, Li W, Kwiatkowski DJ et al (2008). Reversal of learning deficits in a Tsc2+/- mouse model of tuberous sclerosis. Nat Med 14: 843-848.

Ertzgaard P, Campo C, Calabrese A (2017). Efficacy and safety of oral baclofen in the management of spasticity: a rationale for intrathecal baclofen. J Rehabil Med 49: 193-203.

Gogolla N, Leblanc JJ, Quast KB, Sudhof TC, Fagiolini M, Hensch TK (2009). Common circuit defect of excitatory-inhibitory balance in mouse models of autism. I Neurodev Disord 1: 172-181.

Gogolla N, Takesian AE, Feng G, Fagiolini M, Hensch TK (2014). Sensory integration in mouse insular cortex reflects GABA circuit maturation. Neuron 83: 894-905.

Han S, Tai C, Jones CJ, Scheuer T, Catterall WA (2014). Enhancement of inhibitory neurotransmission by GABAA receptors having alpha2,3-subunits ameliorates behavioral deficits in a mouse model of autism. Neuron 81: 1282-1289.

Hanson E, Bernier R, Porche K, Jackson FI, Goin-Kochel RP, Snyder LG et al (2015). The cognitive and behavioral phenotype of the $16 \mathrm{p} 11.2$ deletion in a clinically ascertained population. Biol Psychiatry 77: 785-793.

Henderson C, Wijetunge L, Kinoshita MN, Shumway M, Hammond RS, Postma FR et al (2012). Reversal of disease-related pathologies in the fragile $\mathrm{X}$ mouse model by selective activation of GABAB receptors with arbaclofen. Sci Transl Med 4: 152ra128.

Hippolyte L, Maillard AM, Rodriguez-Herreros B, Pain A, MartinBrevet S, Ferrari C et al (2016). The number of genomic copies at the $16 \mathrm{p} 11.2$ locus modulates language, verbal memory, and inhibition. Biol Psychiatry 80: 129-139.

Horev G, Ellegood J, Lerch JP, Son YE, Muthuswamy L, Vogel H et al (2011). Dosage-dependent phenotypes in models of $16 \mathrm{p} 11.2$ lesions found in autism. Proc Natl Acad Sci USA 108: 17076-17081.

Kelleher RJ 3rd, Bear MF (2008). The autistic neuron: troubled translation? Cell 135: 401-406.

Kolli S, Zito CI, Mossink MH, Wiemer EA, Bennett AM (2004). The major vault protein is a novel substrate for the tyrosine phosphatase SHP-2 and scaffold protein in epidermal growth factor signaling. J Biol Chem 279: 29374-29385.

Leger M, Quiedeville A, Bouet V, Haelewyn B, Boulouard M, Schumann-Bard P et al (2013). Object recognition test in mice. Nat Protoc 8: 2531-2537.

Louros SR, Osterweil EK (2016). Perturbed proteostasis in autism spectrum disorders. J Neurochem 139: 1081-1092.

Michalon A, Sidorov M, Ballard TM, Ozmen L, Spooren W, Wettstein JG et al (2012). Chronic pharmacological mGlu5 inhibition corrects Fragile X in adult mice. Neuron 74: 49-56.

Moreno-De-Luca A, Evans DW, Boomer KB, Hanson E, Bernier R, Goin-Kochel RP et al (2015). The role of parental cognitive, behavioral, and motor profiles in clinical variability in individuals with chromosome 16p11.2 deletions. JAMA Psychiatry 72: 119-126.

Paspalas CD, Perley CC, Venkitaramani DV, Goebel-Goody SM, Zhang Y, Kurup P et al (2008). Major vault protein is expressed along the nucleus-neurite axis and associates with mRNAs in cortical neurons. Cereb Cortex 19: 1666-1677.

Portmann T, Yang M, Mao R, Panagiotakos G, Ellegood J, Dolen G et al (2014). Behavioral abnormalities and circuit defects in the basal ganglia of a mouse model of 16p11.2 deletion syndrome. Cell Rep 7: 1077-1092.

Pucilowska J, Vithayathil J, Tavares EJ, Kelly C, Karlo JC, Landreth GE (2015). The 16p11.2 deletion mouse model of autism exhibits altered cortical progenitor proliferation and brain cytoarchitecture linked to the ERK MAPK pathway. J Neurosci 35: 3190-3200. Qin M, Huang T, Kader M, Krych L, Xia Z, Burlin T et al (2015). RBaclofen reverses a social behavior deficit and elevated protein synthesis in a mouse model of Fragile $\mathrm{X}$ syndrome. Int $J$ Neuropsychopharmacol 18: 1-13. 
Rizzo MA, Hadjimichael OC, Preiningerova J, Vollmer TL (2004). Prevalence and treatment of spasticity reported by multiple sclerosis patients. Mult Scler 10: 589-595.

Rubenstein JL, Merzenich MM (2003). Model of autism: increased ratio of excitation/inhibition in key neural systems. Genes Brain Behav 2: 255-267.

Santoro MR, Bray SM, Warren ST (2012). Molecular mechanisms of fragile X syndrome: a twenty-year perspective. Annu Rev Pathol 7: 219-245.

Sebat J, Lakshmi B, Malhotra D, Troge J, Lese-Martin C, Walsh T et al (2007). Strong association of de novo copy number mutations with autism. Science 316: 445-449.

Silverman JL, Pride MC, Hayes JE, Puhger KR, Butler-Struben HM, Baker $S$ et al (2015). GABAB Receptor agonist R-baclofen reverses social deficits and reduces repetitive behavior in two mouse models of autism. Neuropsychopharmacology 40: 2228-2239.

Silverman JL, Smith DG, Rizzo SJ, Karras MN, Turner SM, Tolu SS et al (2012). Negative allosteric modulation of the mGluR5 receptor reduces repetitive behaviors and rescues social deficits in mouse models of autism. Sci Transl Med 4: 131ra151.

Stoppel LJ, Auerbach BD, Senter RK, Preza AR, Lefkowitz RJ, Bear MF (2017). Beta-Arrestin2 couples metabotropic glutamate receptor 5 to neuronal protein synthesis and is a potential target to treat Fragile X. Cell Rep 18: 2807-2814.

Tao J, Wu H, Coronado AA, de Laittre E, Osterweil EK, Zhang Y et al (2016). Negative allosteric modulation of mGluR5 partially corrects pathophysiology in a mouse model of Rett syndrome. $J$ Neurosci 36: 11946-11958.

Tian D, Stoppel LJ, Heynen AJ, Lindemann L, Jaeschke G, Mills AA et al (2015). Contribution of mGluR5 to pathophysiology in a mouse model of human chromosome 16p11.2 microdeletion. Nat Neurosci 18: 182-184.

Vanhoose AM, Emery M, Jimenez L, Winder DG (2002). ERK activation by G-protein-coupled receptors in mouse brain is receptor identity-specific. J Biol Chem 277: 9049-9053.
Veenstra-VanderWeele J, Cook EH, King BH, Zarevics P, Cherubini $\mathrm{M}$, Walton-Bowen $\mathrm{K}$ et al (2017). Arbaclofen in children and adolescents with autism spectrum disorder: a randomized, controlled, phase 2 trial. Neuropsychopharmacology 42: 1390-1398.

Vogel-Ciernia A, Wood MA (2014). Examining object location and object recognition memory in mice. Curr Protoc Neurosci 69: $83131-17$.

Weiss LA, Shen Y, Korn JM, Arking DE, Miller DT, Fossdal R et al (2008). Association between microdeletion and microduplication at 16p11.2 and autism. N Engl J Med 358: 667-675.

Yang M, Lewis FC, Sarvi MS, Foley GM, Crawley JN (2015a). 16p11.2 Deletion mice display cognitive deficits in touchscreen learning and novelty recognition tasks. Learn Mem 22: 622-632.

Yang M, Mahrt EJ, Lewis F, Foley G, Portmann T, Dolmetsch RE et al (2015b). 16p11.2 deletion syndrome mice display sensory and ultrasonic vocalization deficits during social interactions. Autism Res 8: 507-521.

Zufferey F, Sherr EH, Beckmann ND, Hanson E, Maillard AM, Hippolyte L et al (2012). A $600 \mathrm{~kb}$ deletion syndrome at $16 \mathrm{p} 11.2$ leads to energy imbalance and neuropsychiatric disorders. J Med Genet 49: 660-668.

(c) (i) (2) (2) This work is licensed under a Creative Commons Attribution-NonCommercial-ShareAlike $\quad 4.0$ International License. The images or other third party material in this article are included in the article's Creative Commons license, unless indicated otherwise in the credit line; if the material is not included under the Creative Commons license, users will need to obtain permission from the license holder to reproduce the material. To view a copy of this license, visit http://creativecommons.org/licenses/by-nc-sa/4.0/

(c) The Author(s) 2018 